Crossroads. A Journal of English Studies 6 (3/2014), pp. 28-41

Izabela Olszak

Maria Curie-Skłodowska University, Lublin

\title{
Graphic and semantic organizers as cognitive strategies in reading instruction
}

\begin{abstract}
The present article extends prior research on graphic and semantic organizers principally applied as a reading strategy. Visual representation of information in a text and graphic and semantic organizers refer to different approaches to reading from the traditional, linear text representation. Research demonstrates that powerful metacognitive strategies can be taught to help students monitor and improve their own reading comprehension. This study constitutes an attempt to shed light on the research evidence regarding the effectiveness of graphic and semantic organizers on text learning. As such, it highlights the nature of reading comprehension, various strategies applied in the process of teaching reading, and examples of graphic and semantic organizers for classroom applications.
\end{abstract}

Keywords: graphic and semantic organizers, reading comprehension, reading strategies.

\section{Introduction}

Reading comprehension is one of the most important processes while learning a foreign language. There is a spectrum of definitions concerning reading. Reading is regarded as "a psycholinguistic process by which the reader, a language user, reconstructs as best as he can, a message which has been encoded by a writer as a graphic display" (Goodman, 1971: 22) "Reading comprehension is a process of making sense of a written text. However, it is not a passive one-way decoding process. Instead, it is an active two-way process in which the reader and the text interact, i.e. the reader tests clues from the text against his knowledge to arrive at an understanding of the text acceptable to the reader" (Wong Kee, 1997: 9). Reading comprehension is a complex process involving many subcomponent skills and abilities. Variability in comprehension outcomes has been linked to differences that concern the reader, the text, and factors related to the activity and the level of engagement (Sweet \& Snow, 2003).

What does reading involve? A number of studies have been carried out concerning the subject, nature and factors determining reading comprehension. Researchers and educators are making efforts to build a comprehensive understanding of reading comprehension and its development (Alexander \& The Disciplined Reading and Learning Research Laboratory, 2012; Common Core State Standards Initiative, 2010). Some educators and researchers also try to identify the reasons why some students struggle with the reading tasks they have to carry out at school (e.g., Kamil, 2003; Perie, Grigg \& Donahue, 2005; Van Dijk and Kintsch 1983). The aim of this article is to analyse the most crucial aspects of teaching reading comprehension with the help of graphic and semantic organizers, and to discuss their nature and factors determining the process of comprehending a text. The author also aims to suggest the implementation of some of the examples of the aforementioned organizers in classroom teaching. 


\section{Metacognition in the process of reading comprehension}

Metacognition is defined as "cognition about cognition", or "knowing about knowing". It comes from the root word meta, meaning 'beyond'. It can take many forms; it includes knowledge about when and how to use particular strategies for learning or for problem solving. There are generally two components of metacognition: knowledge about cognition, and regulation of cognition. ${ }^{1}$ In other words, metacognition can be regarded as "thinking about thinking". Good readers use metacognitive strategies to think about and have control over their reading. They implement diverse strategies in the three stages of the process of reading comprehension. Before reading, they define their reading purpose and preview the text. During reading, they monitor their understanding and adjust their reading speed to the difficulty of the text. After reading, they check their understanding of the read text.

There are certain aspects which should be discussed when analyzing the process of reading. Of utmost importance is readers' awareness of the way in which language is used, whether reading in a first or second language. The development of this ability takes a remarkable amount of instructional time and effort. There are two groups of language skills involved in the integration of information across sentences and ideas in a text, namely higher level language skills and lower language skills. The former includes inference and integration, comprehension monitoring, and knowledge about text structure. All of them are essential in order for a reader to construct an integrated and coherent model of a text's meaning. The latter group of language skills represents word reading accuracy and verbal and semantic skills.

Reading comprehension is associated with the creation of a meaning-based representation of the text, often called a mental model or a situation model (Gernsbacher, 1990; Johnson-Laird, 1983; Kintsch, 1998). In order to create an integrated and coherent model of a text both processes, namely integration and inference, are necessary. The local coherence is established due to the integration between adjacent clauses, whereas inferences about different events, actions, and states make the text cohere as a whole (Graesser, Singer, \& Trabasso, 1994). In the case of these two processes, it is necessary that the relevant information, either from the text or world knowledge, be both attainable and accessible. Inference making is regarded as a central component of skilled reading (e.g. Garnham \& Oakhill, 1996; Graesser, Singer, \& Trabasso, 1994). Although less skilled readers are capable of inferential processing, they do not generate as many inferences as more skilled readers do (e.g. Casteel, 1993; Casteel \& Simpson, 1991; Long, Paris \& Upton, 1976). Thus, it is important to establish which factors limit inference making within such populations. An inference can be made only when the requisite general knowledge, necessary to make that inference, is available (e.g. Ackerman, Silver, \& Glickman, 1990; Casteel, 1993). Potential individual differences in inference are often caused by general knowledge differences. There is an example of an inference worksheet attached below.

\footnotetext{
${ }^{1}$ http://en.wikipedia.org/wiki/Metacognition
} 


\section{Inferences Worksheet 2}

Name:

Directions: Read each passage and then respond to the questions. Each question will ask you to make a logical inference based on textual details. Explain your answer by referencing the text.

Kyle ran into his house, slamming the door behind him. He threw his book bag on the floor and plopped on the couch. After six hours of playing Grand Larceny VII, he ate some pizza and fell asleep with a slice in on his belly and his feet on his book bag. When Kyle came home from school the next day, he was noticeably distraught. He balled up his report card and placed it inside of a soup can in the garbage. He then flipped the soup can upside down and relocated garbage from other parts of the can, arranging over the soup can. He then plopped down on the couch and picked up his controller.

1. Why is Kyle distraught?

How do you bor tan?

2. Why does Kyle put the report card in a soup can?

How उo you bor the?

3. Was Kyle's report card good or bad and why was it like that?

How do you bow thas?

Anastasia sat by the fountain in the park with her head in her palms. She was weeping mournfully and wearing all black. In between gasps and sobs, Anastasia cried out a name: "Oh.. John..." And then her cell phone beeped. Her hand ran into her purse and her heart fluttered. The text message was from John. She opened up the message and read the few bare words, "I need to get my jacket back from you." Anastasia threw her head into her arms and continued sobbing.

4. What relationship do John and Anastasia have?

Why so you fool tims wayl

5. Why is Anastasia sad?

How उo you borr tan?

Source: http://www.ereadingworksheets.com/free-r 


\section{Reading comprehension strategies}

There are various strategies applied in the process of reading comprehension. They are different at the stages of production, comprehension, and reproduction of discourse. One group of these may be called linguistic strategies, as it links textual and sentential structures with underlying semantic representations. The second group constitutes the cognitive strategies, as it involves the use of world knowledge, episodic knowledge and cognitive information, for instance opinions, beliefs, attitudes or plans. Before analyzing major strategies of reading comprehension, it is most appropriate to get some insight into the notion of strategy in general.

What exactly does a strategy mean? Is the use of strategies in comprehending a text crucial? There are numerous definitions of strategy to be found. A strategy is "a high level plan to achieve one or more goals under conditions of uncertainty. In the sense of the "art of the general", which included several subsets of skills including "tactics", siegecraft, logistics etc. (Freedman 2013 at IS 1). Mintzberg defined strategy as "a pattern in a stream of decisions" (Mintzberg, 1996: 119). This definition can be contrasted with McKenon's (2011), who argues that "strategy is about shaping the future" and is the human attempt to get to "desirable ends with available means" (McKenon, 2011: 49). Strategy can also be perceived as a type of problem solving (Rumelt, 2011). Rumelt writes that a good strategy has an underlying structure he calls a kernel. The kernel has three parts, namely the diagnosis that explains the nature of the challenge, a guiding policy in order to cope with the challenge, and coherent actions designed to carry out the guiding policy (Rumelt, 2011).

In general, strategies involve various actions, objectives and the concept of optimality. In other words, a strategy is the most relevant way which leads to achieving an aim. A strategy is often described as a cognitive representation of the same actions undertaken to understand something or reach a certain goal. It pertains to complex action sequences, which means that it is related to the notion of a plan. Finally, another common notion usually used in connection with strategies, even as a synonym, is heuristics. This is a system of discovery procedures, namely operations undertaken to acquire knowledge which enables an agent to accomplish a goal or solve precise problems. A heuristic involves typical sorts of strategies which focus on acquiring knowledge that cannot be obtained automatically or obviously. It is often called a general path of proceeding or an outline for finding something (Rumelt, 2011).

The notion of a strategy also presents actions in the strict sense, that is the intended doings of humans. These actions include thinking, problem solving, specific operations and mental steps in order to reach an explicit goal. They are performed under our conscious control, and that is why we cannot or can only partly verbalize or analyze them. In general, strategies are the result of a mental process linked with much information. Cognitive strategies appear if the process of gaining knowledge is consciously controlled and each step yields the information decisive for the next steps. What is crucial in the whole process? It is extremely vital to select or come up with a strategy that is good and fast in the understanding of new knowledge. A strategy will, in general, encompass higher levels of information processing, that is, the high-level strategic attempts of a problem solver (Newell and Simon, 1972). It also happens that the problem is analyzed as being divided into sub problems if it is perceived as complex or with no obvious solution. There is another more general strategic procedure which compares the nature of the obtained goal at the beginning and in the final stage of analyzing. A strategy is often understood as a production system which gives 
information about problematic phenomena (Newell and Simon, 1972). The integration of newly found information into the knowledge set and old information leads to acquiring a certain strategy. It is important for our analysis that strategies in these cases also consist of stepwise, complex acts which lead to a certain aim. Moreover, at each stage of the dispute several options are viable, and at the same time defined knowledge is accessible about context, consequences, participants and actions.

From the preceding discussion, we can find out information about the definition and nature of strategies. For further dispute, it is still vital to establish the connection between applying the cognitive strategies and the process of teaching reading. It is necessary to present to what extent both aspects are dependent. Reading behaviours (i.e. strategies and skills applied while reading a text) in the emergent stage of literacy, when children are not yet conventionally decoding print, focus later reading comprehension. What do we understand by the expression reading comprehension strategies? They constitute a conscious plan or a set of steps that good readers use to make sense of text. They assist students in becoming determined, active readers who control their own reading comprehension. Readers differ in the way they comprehend texts. The differences are more often described in relation to two different levels of processing. The first level is reading accuracy and speed, and the second is about linguistic and cognitive abilities (e.g. working memory, integration of information, inference, and the use of metacognitive strategies; Cain, Oakhill, Barnes \& Bryant, 2001). Both levels are of the same importance. In addition, the insufficient development of lower level skills may prevent the deployment of higher level processes because of inaccurate or laborious reading (Hoover \& Gough, 1990; Stanovich, 1991).

"Reading comprehension is a complex process which involves conscious and unconscious use of various strategies to build a model of the meaning which the writer is assumed to have intended. The model is constructed using schematic knowledge structures and the various cue systems the writer has given (e.g., words, syntax, macro- structures, social information) to generate hypotheses which are tested using various logical and pragmatic strategies" (Johnston, 1983: 103). There are seven in order to have a firm scientific basis for ameliorating text comprehension, namely: previewing, contextualizing, questioning to understand and remember, reflecting on challenges to your beliefs and values, outlining and summarizing, evaluating an argument, and comparing and contrasting related readings. Students are already familiar with various reading strategies in their native language. However, it is extremely necessary to re-train them so that they can successfully apply the techniques to a second language.

\section{Taxonomy of strategies}

One of the fundamental aspects in the process of developing reading comprehension is language learning strategies. The long-term process of teaching various strategies takes place at school, since students are taught how to synchronize traditional memory and comprehension strategies along with interpretative processes. Below, there are numerous strategies that can be adapted in the process of teaching reading comprehension.

\begin{tabular}{|l|l|l|}
\hline \multicolumn{2}{|l|}{ DIRECT STRATEGIES } & definition/procedure \\
\hline category & $\begin{array}{l}\text { - Creating mental } \\
\text { connections }\end{array}$ & $\begin{array}{l}\text { contextualizing/associating } \\
\text { words, semantic mapping, }\end{array}$ \\
\hline MEMORY
\end{tabular}




\begin{tabular}{|c|c|c|}
\hline & $\begin{array}{l}\text { - Applying images and } \\
\text { sounds } \\
\text { - Reviewing } \\
\text { - Employing action }\end{array}$ & $\begin{array}{l}\text { creating mental images, } \\
\text { providing keywords, } \\
\text { reviewing words after longer } \\
\text { intervals, applying } \\
\text { mechanical techniques, }\end{array}$ \\
\hline COGNITIVE & $\begin{array}{l}\text { - Practicing } \\
\text { - Receiving and sending } \\
\text { messages } \\
\text { - Analyzing and reasoning } \\
\text { - Creating structure for input } \\
\text { and output }\end{array}$ & $\begin{array}{l}\text { repeating, recombining, } \\
\text { using resources, quickly } \\
\text { getting the idea, translating, } \\
\text { transferring, deduction, } \\
\text { taking notes, highlighting, } \\
\text { summarizing }\end{array}$ \\
\hline $\begin{array}{l}\text { COMPENSATION } \\
\text { STRATEGIES }\end{array}$ & $\begin{array}{l}\text { - Guessing intelligently } \\
\text { - Overcoming limitations in } \\
\text { speaking and writing }\end{array}$ & $\begin{array}{l}\text { using various linguistic clues, } \\
\text { approximating, selecting } \\
\text { topics, applying gestures, } \\
\text { coining words, }\end{array}$ \\
\hline \multicolumn{3}{|l|}{ INDIRECT STRATEGIES } \\
\hline $\begin{array}{l}\text { METACOGNITIVE } \\
\text { STRATEGIES }\end{array}$ & $\begin{array}{l}\text { - Centering your learning } \\
\text { - Arranging and planning } \\
\text { your learning } \\
\text { - Evaluating your learning }\end{array}$ & $\begin{array}{l}\text { linking, overviewing, paying } \\
\text { attention, metalinguistics, } \\
\text { planning learning, } \\
\text { establishing goals, self- } \\
\text { monitoring, self-evaluating, }\end{array}$ \\
\hline AFFECTIVE STRATEGIES & $\begin{array}{l}\text { - Lowering your anxiety } \\
\text { - Encouraging yourself } \\
\text { - Taking your emotional } \\
\text { temperature }\end{array}$ & $\begin{array}{l}\text { relaxation, mediation, music, } \\
\text { laughter, positive statements, } \\
\text { rewarding yourself, body } \\
\text { awareness, emotion } \\
\text { checklist, }\end{array}$ \\
\hline SOCIAL STRATEGIES & $\begin{array}{l}\text { - Asking questions } \\
\text { - Cooperating with others } \\
\text { - Empathizing with others }\end{array}$ & $\begin{array}{l}\text { clarification, verification, } \\
\text { correction, peer support, } \\
\text { interaction, developing } \\
\text { cultural understanding, }\end{array}$ \\
\hline
\end{tabular}

Source: R. Oxford, 1990 http://mste.illinois.edu/courses/ci407su02/students/stansell/Strategies.htm

Learning strategies are often characterized as "specific actions, behaviors, steps, or techniques - such as seeking out conversation partners, or giving oneself encouragement to tackle a difficult language task -used by students to enhance their own learning"(Scarcella \& Oxford, 1992: 63). Although there are numerous definitions concerning reading strategies, researchers agree that reading strategies are conscious actions undertaken by learners to achieve specific reading goals. Reading strategies constitute essential factors while developing effective reading practices. Researchers claim that both direct and indirect use of reading strategies lead to the improvement of reading comprehension ability.

\section{Strategy training vs. motivation}

Motivation is a fundamental factor when developing reading comprehension skills. Theories concerning motivational strategies aim to explain why learners behave and think as they do. Motivation is vital in the whole process of education, and there are various sources of it. Crump (1995) points out that the main sources of motivation include excitement, interest, keenness, and enthusiasm towards learning. The levels and kinds of motivation differ from individual to individual. In other words, students may have various levels and amounts of 
motivation, as well as different kinds of motivation. Teachers and students often perceive motivation as a factor which determines success or failure in learning. Undoubtedly, motivation and its strategies are the primary impetus to launch foreign language learning.

Cook (2000) claims that language acquisition varies with learners. Furthermore, he adds that there are three main elements which concern and influence the acquisition of foreign language, namely age, personality, and motivation. Moreover, he highlights that among the above three issues motivation is the most crucial element in foreign language learning.

\begin{tabular}{|l|l|}
\hline Types of motivation & Definition \\
\hline 1. Integrative & $\begin{array}{l}\text { learning the language with the objective of } \\
\text { participating in the culture of its inhabitants }\end{array}$ \\
\hline 2. Instrumental & $\begin{array}{l}\text { implies that a learner acquires the language } \\
\text { in support of an aim relating to occupation }\end{array}$ \\
\hline 3. Intrinsic & $\begin{array}{l}\text { involves eagerness to participate in certain } \\
\text { activities because a learner feels that they are } \\
\text { attractive }\end{array}$ \\
\hline 4. Extrinsic & $\begin{array}{l}\text { constitutes a tendency to engage in activities } \\
\text { because of reasons which are not linked to } \\
\text { the activity (e.g. reward or punishment) }\end{array}$ \\
\hline
\end{tabular}

Source: Dörnyei, 1994; http://seas3.elte.hu/coursematerial/

\section{Collaborative reading}

Collaboration is very significant in developing students' reading literacy, but abuse of it will be a waste of time and will not bring good results in teaching reading. It is important to support students' engagement with various reading behaviours, e.g. strategies and skills, and to engage them in some social reading experiences such as peer reading at school, or adultchild reading at home. These social interactions are a critical aspect of emergent literacy instructions (Paterson, Henry, O'Quin, Ceprano \& Blue, 2003). From a socio-constructivist perspective (e.g. Vygotsky, 1978) these social interactions support children's engagement with reading behaviours in two ways: (1) they model the use of reading behaviours, and (2) they structure reading behaviours through the use of questions or prompts to help children learn when and how to engage with reading behaviours. In order to better understand these methods, one should study the interactions that arise in these social reading contexts and analyze how they are related to children's engagement with reading behaviours. Vygotsky (1978), known for his theory of social constructivism, believes that learning and development is a collaborative activity. Students are cognitively developed in the context of socialization and education. For learning to occur, the child first makes contact with the social environment on an interpersonal level and then internalizes this experience. Earlier notions and new experiences influence the child, who then constructs new ideas (Vygotsky, 1978). According to the constructivist theories, learning is a social advancement that involves language, real world situations, and interaction and collaboration among learners. The learners are considered to be central in the learning process.

\section{Monitoring comprehension}


Monitoring one's reading comprehension means being able to understand what one reads. Such students possess strategies to "fix" obstacles in their understanding as the obstacle arises. Broad research in this field shows that instruction, even in the early grades, can help students become fluent at monitoring their comprehension. Applying comprehension monitoring instruction allows students to be aware of what they do to understand, pinpoint what they do not understand, or adopt appropriate strategies to resolve problems in reading comprehension. As Lehr \& Osborne (2006) expressed it:

What they found was that good readers achieve comprehension because they are able to use certain procedures - labeled comprehension strategies by the researchers - to relate ideas in a text to what they already know; to keep track of how well they are understanding what they read; and, when understanding breaks down, to identify what is causing the problem and how to overcome it. (Lehr \& Osborne, 2006).

Students use several comprehension monitoring strategies, for instance: they identify where the difficulty in the text occurs and what it is, restate the difficult sentence or passage in their own words, look back through the text, and look forward in the text for information that might help them to resolve the difficulty.

\section{Graphic and semantic organizers}

Graphic organizers help to illustrate concepts and relationships between concepts in a text. They are given different names, such as maps, webs, graphs, charts, frames, or clusters. They are extremely helpful in the process of reading comprehension as they assist readers in focusing on concepts and the way they are connected to other concepts. Graphic and semantic organizers, originally called advanced organizers and then structured overviews, were primarily initiated by Richard Barron (Barron, 1969), but have their roots in Ausubel's work. According to his cognitive theory of meaningful verbal learning, the use of graphic and semantic organizers intensifies students' learning and retention of unfamiliar but meaningful materials (Ausubel, 1960). His assumption was that new information is acquired when it is linked to the learners' already existing cognitive structure (1968). Therefore, the function of these organizers is to stimulate students' prior knowledge and link the new material to the previously stored information, providing optimal anchorage and rendering the new material more familiar and meaningful (Ausubel, 1960).

Another theory which is consistent with the above-mentioned is the schema theory (Anderson \& Pearson, 1984). Those authors claimed that the mind is composed of cognitive structures of knowledge, known as background knowledge, which obtain and assimilate the newly acquired information in order to enhance learning and retention of information. One has to find a "mental home" for the information in the text, or alter an existing one in order to accommodate the new knowledge (Anderson \& Pearson, 1984).

There are numerous advantages of applying graphic organizers, for instance they: help students focus on text structure differences between fiction and nonfiction as they read; they provide students with tools they can use to examine and show relationships in a text; they help students write well-organized summaries of a text.

Graphic and semantic organizers are visual and spatial ways to construct and represent ideas from texts, such as using tables and grids, Venn diagrams, plot organizers, or concept webs. Teachers need to show students how to select and use graphic organizers as thinking tools, supporting them to activate prior knowledge, develop new vocabulary, or show relationships between concepts (Trehearne, 2006:159). Interestingly, English as a Second 
Language students and students with learning disabilities particularly benefit from their use (Trehearne, 2006). Some examples of graphic organizers:

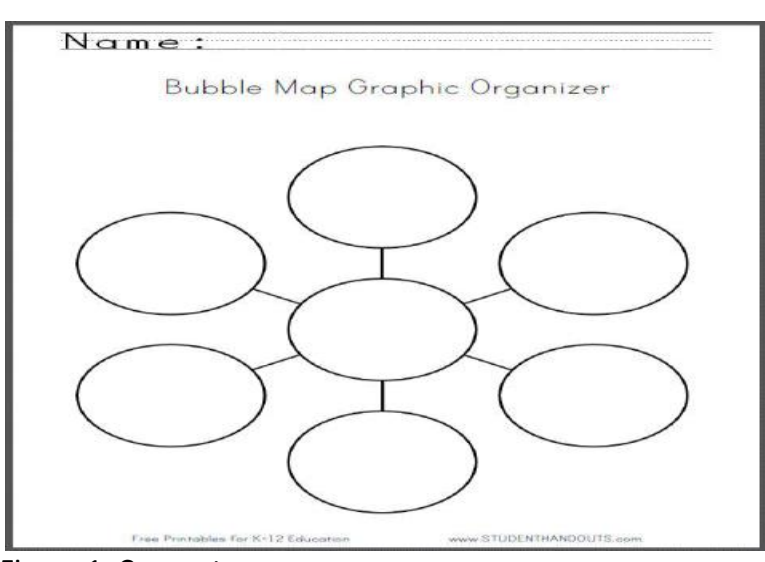

Figure 1. Concept map

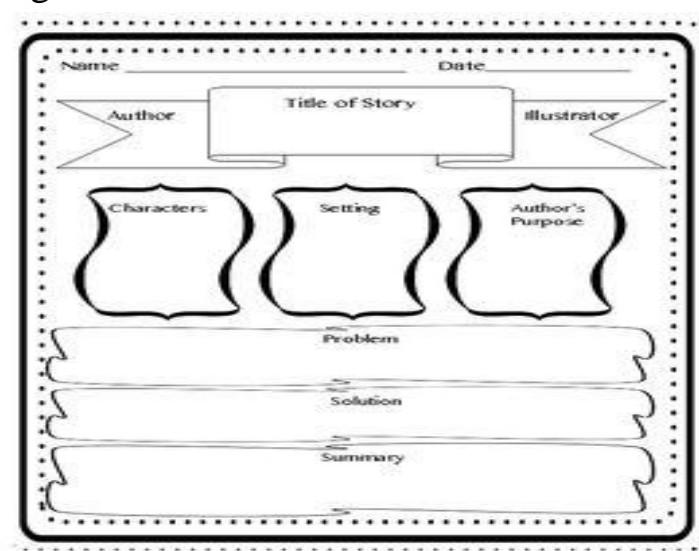

Figure 2. Concept map 1

Source: https://www.pinterest.com/pin/8479440545

Semantic maps or webs are visual tools to highlight relationships between facts after reading an information text (See Figure 1 and 2). Alternatively, they can be used to show relationships between characters, settings, or events after reading narratives. These techniques are equally useful for organizing concepts before reading about a topic, becoming a tool for activating prior knowledge.
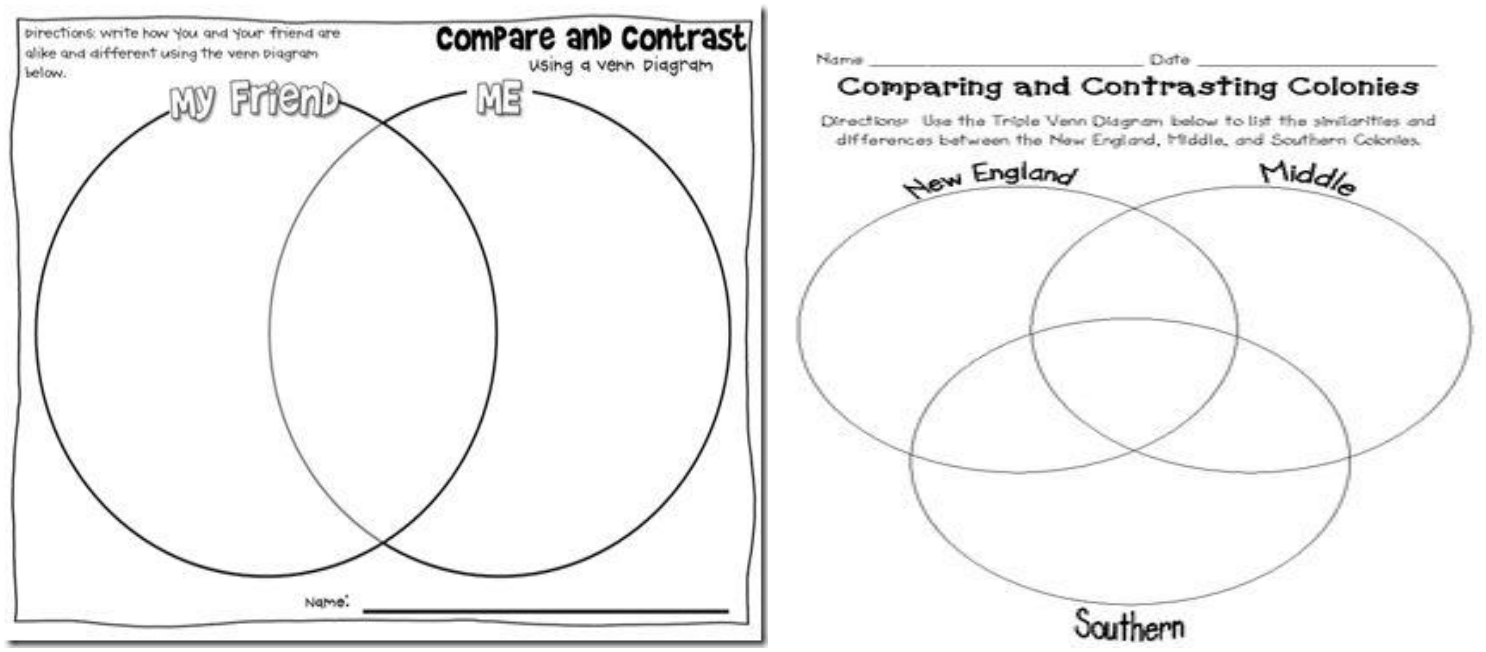

Figure 3. Venn diagram 1

Figure 4. Venn diagram 2

Venn diagrams are useful graphics for comparing and contrasting the attributes of two or more things (See Figure 3 and 4). The teacher selects a non-fiction text about a research theme, such as regions in the UK, colonial times, or relationships, and students have to identity what is the same or different about two or three items. Alternatively, a fiction text can be used, with good character development, and students identify what is the same or different about two main characters.

Another type of graphic organizer (See Figure 5), which is mainly used in expository texts, is the matrix. This is a kind of input table, which confines the sum of the desired information within its square (Graney, 1992; Kang, 2004). It is used to delineate important categories or relationships, and depict similarities and disparities between two or more people, 
things, places or events (Graney, 1992; Jones, Pierce, \& Hunter, 1989). In order to design a matrix, learners need to identify which main aspects they wish to focus on and what types of relationships they wish to highlight (Graney, 1992). The matrix has the additional advantage of presenting concept relations both hierarchically/vertically and horizontally in a twodimensional form facilitating the extraction of information.

\section{Compare/Contrast Matrix}

\begin{tabular}{|l|l|l|}
\hline \multicolumn{2}{c}{ Name 1 } & Name 2 \\
\hline Attribute 1 & & \\
\hline Attribute 1 & & \\
\hline Attribute 1 & & \\
\hline
\end{tabular}

Figure 5. Matrix

Another example of a graphic organizer connected with improving reading comprehension is the story map (See Figures 6 and 7, Story map). It uses a graphic organizer to help students learn the elements of a story or a book. Students become thoroughly engaged in the plot, setting, problem and solution, and learn the details. There are various types of story map graphic organizer. The most basic focus is at the beginning, middle, and end of the story. Below is an example of such a story map.

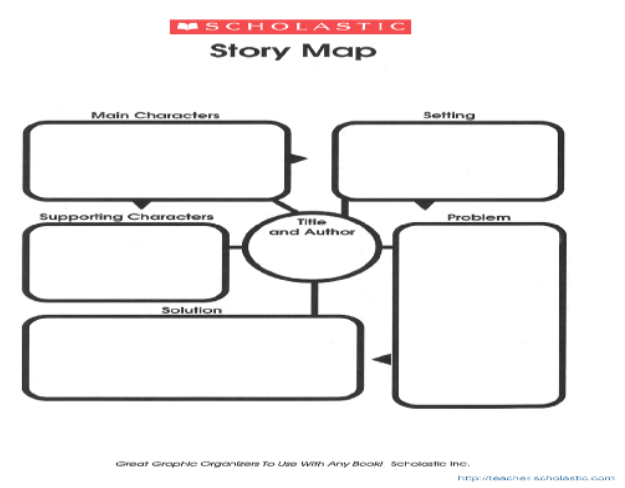

Figure 6. Story map 1

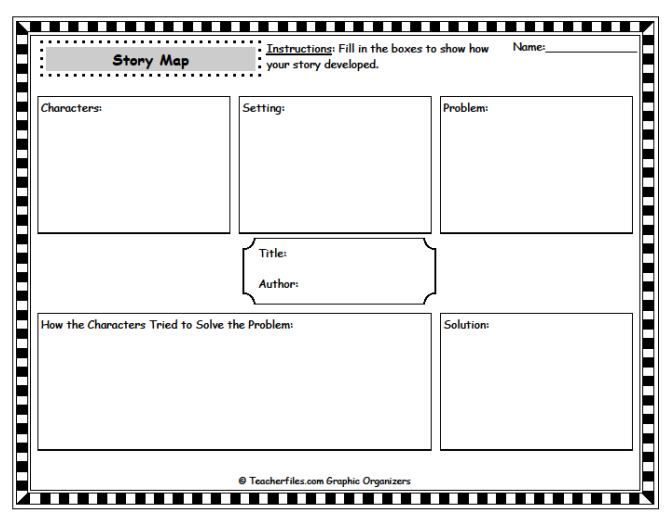

Figure 7. Story map 2

Source: http://www.readingrockets.org/strategies

Another example is the semantic map or, in other words, web-like organizers. There are various names for these, for instance: mind maps, spider maps or sunbursts. They look "like a sun or star with rays emanating from it, as they consist of a circle with lines radiating from the circle" (Graney, 1992: 164). They can be used to represent words, ideas, or other items linked to and arranged around a central key word or idea of the text, and depict relationships of the different components of an idea to the main idea, that is of the part to the whole (Graney, 1992). These maps place the main idea in the centre around the relevant notion. They offer an overview of key vocabulary and concepts, providing a link between what students know and what they will learn and read, a type of brainstorming activity mainly 
used before reading a passage to stimulate students' background cognitive structure and to assess their knowledge in terms of the specific topic (Vaughn \& Edmonds, 2006).

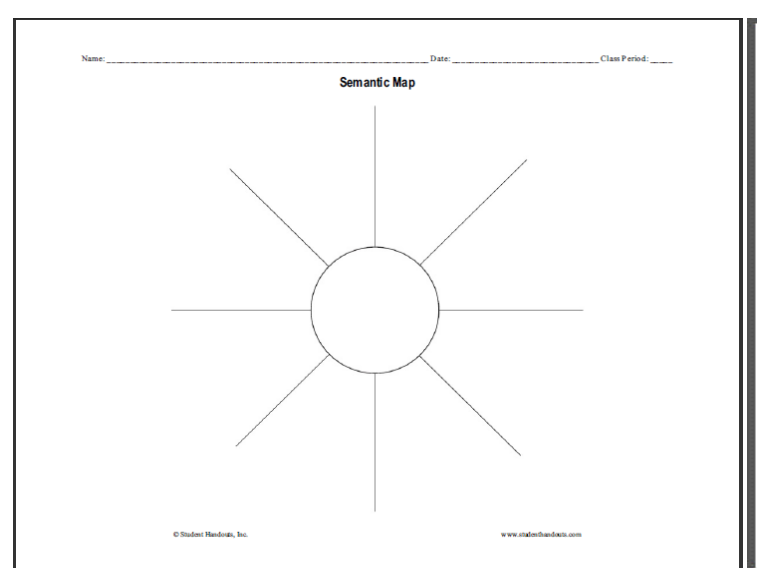

Figure 8. Semantic map

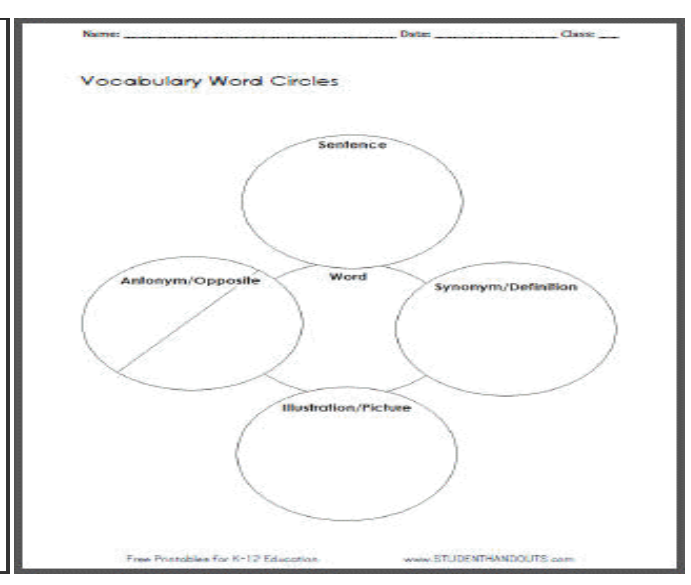

Figure 9. Semantic map

Source: http://www.studenthandouts.com/01-Web-Pages/K-6-ELA-Worksheets/ELA-Worksheets/VocabularyWord-Circles.htm

Some examples of online-generated techniques:

\section{Webbing}

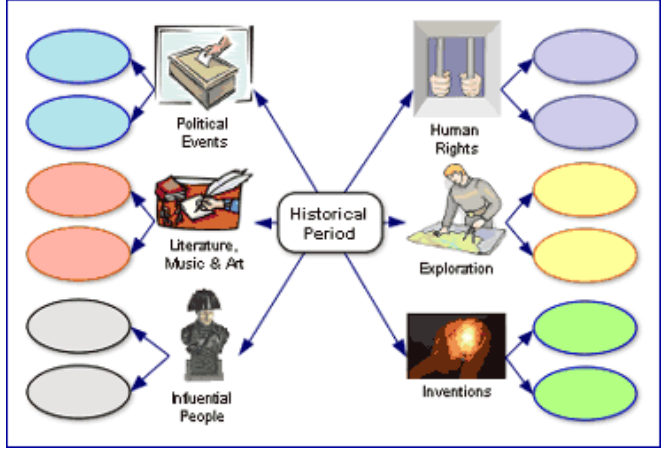

http://www.inspiration.com/visual-learning

2. Online reading skills practice

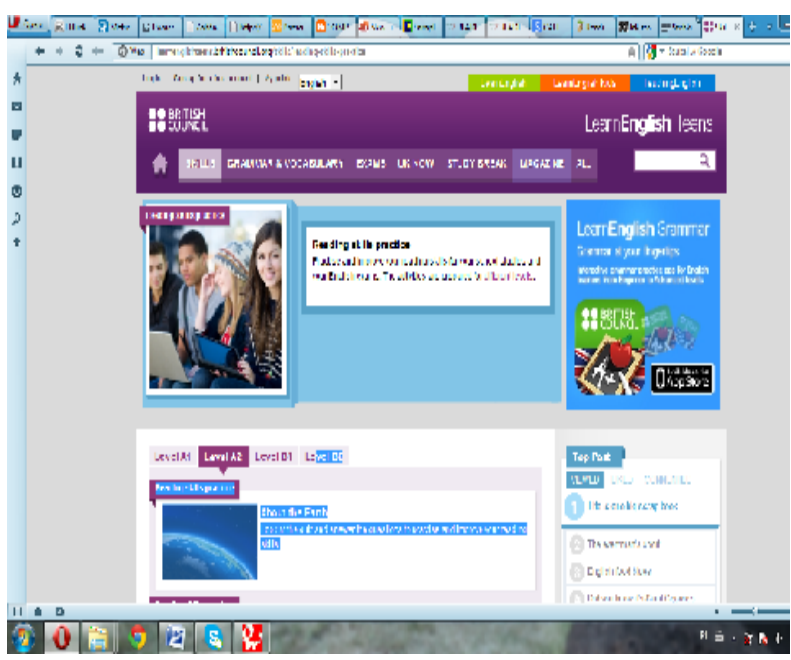

This is a visual map that presents different data related to one another. Webbing is typically used by learners, students, teachers and other professionals as brainstorming strategies for developing and connecting ideas while developing reading comprehension.

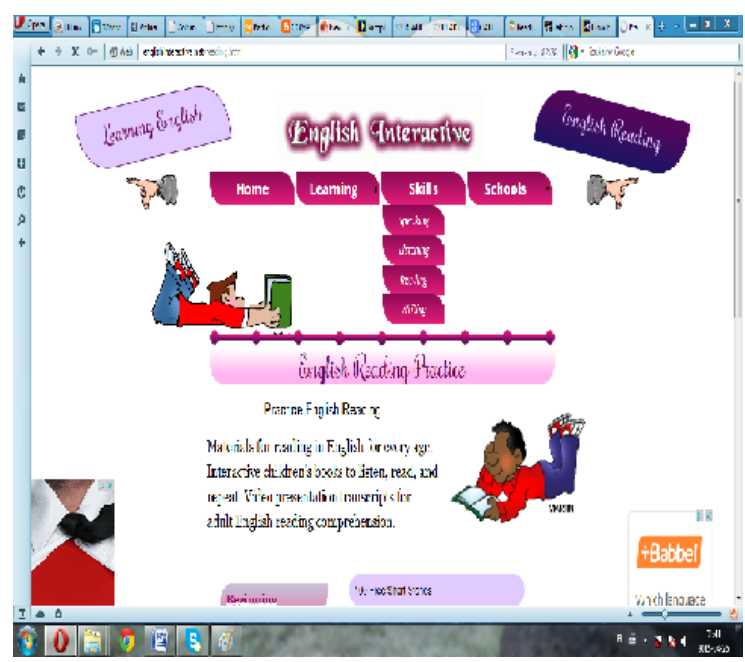


Summing up, the literature review shows that graphic and semantic organizers have been successfully deployed with students during and after reading texts. As visual scaffolds they are conducive to activating prior knowledge, gaining an insight into text structure, and identifying as well as connecting the main ideas of a text, resulting thus in better recall and retention of information for the students. Bearing in mind all the benefits of graphic and semantic organizers, teachers should implement this strategy in classrooms and train students in using it in order to help them become independent and self-regulated learners, especially after long-term interventions.

\section{References}

Ackerman, B. P., Silver, D., \& Glickman, I. 1990. Concept availability in the causal inferences of children and adults. Child Development, 61, 230-246.

Anderson, R. C., \& Pearson, P. D. 1984. A schema-theoretic view of basic processes in reading comprehension. In P. D. Pearson (Ed.), Handbook of reading research (pp. 255291). New York: Longman.

Ausubel, D. P. 1968. Educational psychology: A cognitive view. New York: Holt, Rinehart, \& Winston.

Cain, K., Oakhill, J. V., Barnes, M. A., \& Bryant, P. E. 2001. Comprehension skill, inference making ability, and the relation to knowledge. Memory and Cognition, 29,

Casteel, M. A. 1993. Effects of inference necessity and reading goal on children's inference generation. Developmental Psychology, 29, 346-357.

Casteel, M. A., \& Simpson, G. B. 1991. Textual coherence and the development of inferential generation skills. Journal of Research in Reading, 14, 116-129.

Common Core State Standards Initiative 2010. Common core state standards for English language arts and literacy in history/social studies, science, and technical subjects. Washington, DC: Council of Chief State School Officers and National Governors Association. Available from: http://www.corestandards.org/

Crump, C. A. 1995. "Motivating students: A teacher's challenge". Sooner Communication Conference, Norman, Oklahoma. Cook, V. 2000. Linguistics and second language acquisition. Beijing: Foreign Language Teaching and Research Press and Macmillan Publishers Ltd.

Freedman, Lawrence. 2013. Strategy. Oxford University Press.

Garnham, A., \& Oakhill, J. V. 1996. The mental models theory of language comprehension. In B. K. Britton \& A. C. Graesser (Eds.), Models of understanding text (pp. 313-339). Hillsdale, NJ: Erlbaum.

Gernsbacher, M. A. 1990. Language comprehension as structure building. Hillsdale, NJ: Erlbaum.

Graesser, A. C., Singer, M., \& Trabasso, T. 1994. Constructing inferences during narrative text comprehension. Psychological Review 101, 371-395.

Graney, M. J. 1992. A framework for using text graphing. System 20, 161-167. 
Hoover, W.A. and Gough, P.B. 1990. The simple view of reading. Reading and Writing: An Interdisciplinary Journal 2, 127-160.

Johnson-Laird, P. N. 1983. Mental models. Cambridge, England: Cambridge University Press.

Kamil, M.L. 2003. Adolescents and literacy: Reading for the 21st century. Washington, DC: Alliance for Excellent Education.

Kintsch, W. 1998. Comprehension: A paradigm for cognition. New York: Cambridge University Press.

Mintzberg, Henry and, Quinn, James Brian. 1996. The Strategy Process: Concepts, Contexts, Cases. Prentice Hall.

Organisation for Economic Co-operation and Development. 2010. Education at a glance 2010: OECD Indicators. Available from: http://www.oecd.org/education/skills-beyondschool/45926093.pdf

Paris, S. G., \& Upton, L. R. 1976. Children's memory for inferential relations in prose. Child Development, 47, 660-668.

Paterson, W., Henry, J., O'Quin, K., Ceprano, M. \& Blue, E. 2003. Investigating the effectiveness of an integrated learning system on early emergent readers. Reading Research Quarterly, 38(2), 172-207. doi:10.1598/RRQ.38.2.2.

Perie, M., Grigg, W. \& Donahue, P. 2005. The nation's report card: Reading 2005. Washington, DC: US Department of Education, National Center for Education Statistics.

Rumelt, Richard P. 2011. Good Strategy/Bad Strategy. Crown Business. ISBN 978-0-30788623-1.

Scarcella, R. \& Oxford, R., 1992: The Tapestry of Language Learning: The Individual in the

Communicative Classroom. Boston: Heinle \& Heinle.

Stanovich, K. E. 1991. Cognitive science meets beginning reading. Psychological Science

Sweet, A. P. , \& Snow , C. E. (Eds.). 2003. Rethinking reading comprehension . New York , NY : Guilford.

Trehearne, M. P. (Ed.). 2006. Comprehensive literacy research for grades 3-6 teachers. Vernon Hills: ETA/Cuisenaire.

Van Dijk, T.A. \& Kintsch, W. 1983. Strategies of discourse comprehension. New York: Academic Press.

Vaughn, S., \& Edmonds, M. 2006. Reading comprehension for older readers. Intervention in School and Clinic, 41, 131-137.

Vygotsky, L.S. 1978. Mind in society: The development of higher psychological processes. Cambridge, MA: Harvard University Press.

IS 1: http://www.twitch.tv/tankstriker/profile/followers (December 2014) 
Crossroads. A Journal of English Studies 6 (3/2014), pp. 28-41 